\title{
Comparative Transcriptome Analysis of Streptomyces Clavuligerus in Response to Favorable and Restrictive Nutritional Conditions
}

\author{
Laura Pinilla ${ }^{1}$, León F. Toro ${ }^{1}{ }^{\circledR}$, Emma Laing ${ }^{2}$, Juan Fernando Alzate ${ }^{3}$ and \\ Rigoberto Ríos-Estepa $4, *$ (D) \\ 1 Grupo de Bioprocesos, Universidad de Antioquia, Calle, Medellín 70 No. 52-21, Colombia \\ 2 Department of Microbial Sciences, School of Biosciences and Medicine, University of Surrey, \\ Guildford GU2 7XH, UK \\ 3 Group of Parasitology, School of Medicine, Universidad de Antioquia, Calle, Medellín 70 No. 52-21, \\ Colombia \\ 4 Grupo de Bioprocesos, Departamento de Ingeniería Química, Universidad de Antioquia, Calle, \\ Medellín 70 No. 52-21, Colombia \\ * Correspondence: rigoberto.rios@udea.edu.co; Tel.: +57-4-2198568; Fax: +57-4-2638282
}

Received: 18 May 2019; Accepted: 9 July 2019; Published: 19 July 2019

\begin{abstract}
Background: Clavulanic acid (CA), a $\beta$-lactamase inhibitor, is industrially produced by the fermentation of Streptomyces clavuligerus. The efficiency of CA production is associated with media composition, culture conditions and physiological and genetic strain characteristics. However, the molecular pathways that govern CA regulation in S. clavuligerus remain unknown. Methods and Results: Here we used RNA-seq to perform a comparative transcriptome analysis of S. clavuligerus ATCC 27064 wild-type strain grown in both a favorable soybean-based medium and in limited media conditions to further contribute to the understanding of $S$. clavuligerus metabolism and its regulation. A total of 350 genes were found to be differentially expressed between conditions; 245 genes were up-regulated in favorable conditions compared to unfavorable. Conclusion: The up-regulated expression of many regulatory and biosynthetic CA genes was positively associated with the favorable complex media condition along with pleiotropic regulators, including proteases and some genes whose biological function have not been previously reported. Knowledge from differences between transcriptomes from complex/defined media represents an advance in the understanding of regulatory paths involved in S. clavuligerus' metabolic response, enabling the rational design of future experiments.
\end{abstract}

Keywords: transcriptomic analysis; Streptomyces clavuligerus; gene expression; clavulanic acid; complex media; gene cluster

\section{Introduction}

Clavulanic acid (CA) is a potent $\beta$-lactamase inhibitor; it increases the stability and half-life of $\beta$-lactam antibiotics [1]. All CA clinically used is obtained by fermentation of Streptomyces clavuligerus species; this actinomycete is a producer of a large variety of secondary metabolites with different biological activities e.g., cephamycin C (cephC) and various compounds with clavam structure with antifungal and antitumor activities [2].

The biosynthetic pathway leading to CA starts with the condensation of the amino acid L-arginine (precursor $\mathrm{C}_{5}$ ), and the glycolytic intermediate glyceraldehyde-3-phosphate (GAP), (precursor $\mathrm{C}_{3}$ ). The reaction is mediated by $\mathrm{N}_{2}$-(2-carboxyethyl)-arginine synthetase (CeaS) producing the acyclic compound $\mathrm{N}_{2}$-(2-carboxyethyl) arginine, which, after successive oxidation-reduction reactions, gives 
rise to clavaminic acid, which differs from CA in its stereochemistry [3]. The conversion of clavaminic acid to CA requires the inversion of the stereochemistry of the ring system to form CA. The structural similarities between CA and 5S clavams reflect shared elements of a common biosynthetic pathway. The steps shared in the biosynthetic pathways are called "early stages", which lead to the last common intermediate, clavaminic acid. The specific stages, used for the production of CA or 5S clavams, are called "late stages" (Figure 1) [4].

\section{Early stages}

Glyceraldehyde 3-phosphate<smiles>NC(N)C(=O)OCC(O)C=O</smiles>

L-Arginine<smiles>CC(C)C1CC2CC(=O)N2C1C(=O)O</smiles>

$\mathrm{H}$<smiles>CCCCCCCCC(O)C(C(=O)O)N1CCC1=O</smiles>

Proclavaminic acid
L-N2-(2-Carboxyethyl)arginine

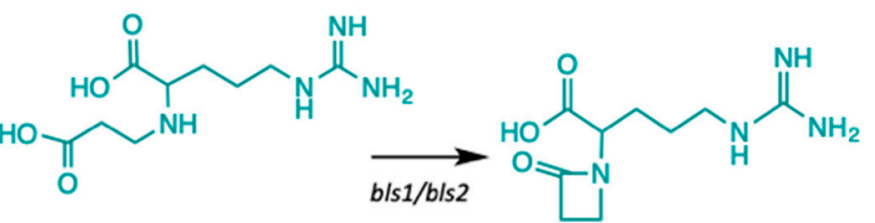

Deoxyguanidinoproclavaminic acid<smiles>CC(C)(C)CCCNC(=N)N</smiles>

Guanidinoproclavaminic acid

Dihydro-clavaminic acid

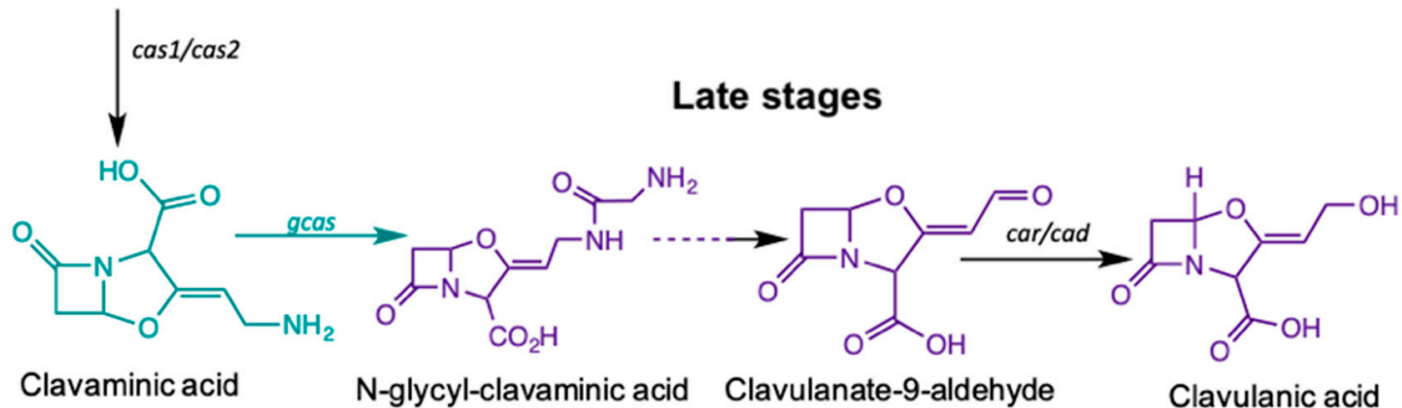

Clavaminic acid

$\mathrm{N}$-glycyl-clavaminic acid

Clavulanate-9-aldehyde

Clavulanic acid

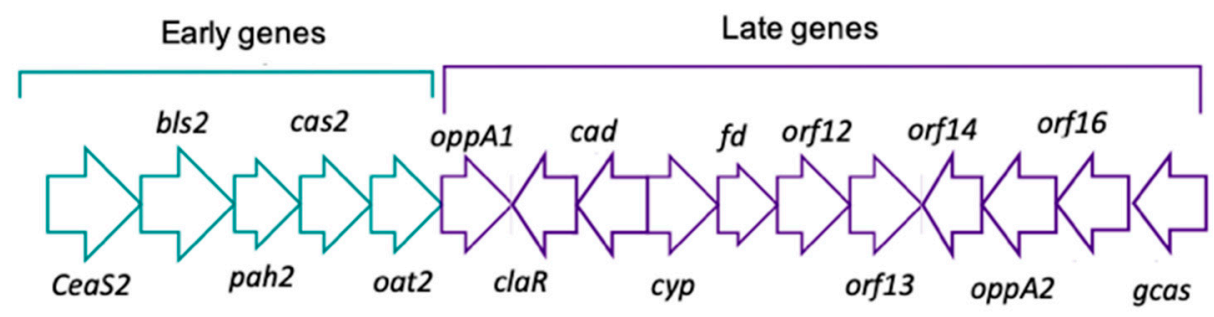

Figure 1. Clavulanic acid metabolic pathway.

The production of secondary metabolites in Streptomyces sp. depends, in part, on growth and morphological differentiation; these processes are triggered in response to nutrient shortage, mainly during the stationary phase $[3,5,6]$. S. clavuligerus also presents a complex life cycle in which germinative spores develop giving rise to a multinucleated mycelial substrate that later becomes aerial mycelium; this initiates a process of regular septation along with the aerial hyphae, ending in uninucleate long chain spores that, once separated, lead to germinative spores that initiate the life cycle again. After initiation of the morphological differentiation process, secondary metabolites generally begin to 
be synthesized. The expression of genes, required for these two events, are regulated in a coordinated manner [7].

Despite numerous studies, the regulatory mechanisms present in the CA biosynthesis pathway are yet to be identified. CA production is controlled by a group of regulatory genes; however, most studies have focused on individual genes. In order to develop a rational genetic engineering approach for secondary metabolite production it is necessary to use modern methods to obtain information on the temporal and conditional expression of global regulatory factors, specific-pathway regulators and limiting enzyme production rates. Hence, the application of transcriptomics to $S$. clavuligerus, growing at different stages of cell development and/or environmental conditions, might contribute to elucidate regulatory paths [8-11].

Due to the clinical and industrial interest of CA, most studies on $S$. clavuligerus have been directed to increase its production titers, evaluating the impact of culture media composition and environmental conditions [6,12], metabolic engineering [13], transcriptional analysis (microarrays) and recently, metabolic network and systems biology analysis [14-18]. Recently, the use of data from RNA-seq experiments has greatly contributed to increase our understanding of regulatory networks in diverse microorganisms. Transcriptomics enables quantitative measurements of mRNA expression and variations between different states, thus reflecting the genes that are being overexpressed or downregulated at particular times and conditions [11]. The main goal of these experiments is to identify the differentially expressed genes in two or more conditions selected based on a combination of expression change threshold and score cutoff, which are usually based on $\mathrm{P}$ values generated by statistical modeling [19].

Data from RNA-Seq have proved to be particularly useful in the study of cell metabolic performance through the study of transcriptional regulators and differential gene expression analysis [11], thus contributing to strain optimization studies, using metabolic engineering tools. As a result, a better understanding of the metabolic pathways and regulatory mechanisms involved in the biosynthesis of important metabolites, such as CA, has been gained.

In this study, we performed a comparative transcriptome analysis of $S$. clavuligerus subjected to two culture conditions, growing cells in a nutrient-deficient medium, unfavorable for CA biosynthesis, and in nutrient conditions favorable for CA biosynthesis, using a soybean-based medium. The study aimed to contribute to further understanding of secondary metabolism and potential regulatory mechanisms that might be involved in CA synthesis.

\section{Results}

\subsection{Shake-Flask Cultivations Under Different Culture Conditions}

Figure 2A,B show profiles for substrate consumption and product biosynthesis using the S. clavuligerus ATCC27064 strain, grown in minimal GSPG and soybean-based SB-M media, respectively.

As observed, the phosphate source was completely depleted at $75 \mathrm{~h}$ in GSPG; meanwhile, in SB-M, the phosphate consumption was slower, rendering a residual concentration of $0.82 \mathrm{~g} / \mathrm{L}$ at $114 \mathrm{~h}$. The main carbon source, glycerol, was completely consumed at $75 \mathrm{~h}$ in GSPG, in contrast to SB-M for which the lowest concentration was obtained at $114 \mathrm{~h} ; 0.08 \mathrm{~g} / \mathrm{L}$ of glycerol remained unused in SB-M due to the presence of alternative carbon sources such as starch, peptides and carbohydrates in isolated soybean protein $[20,21]$. CA production was considerably higher in SB-M $(1015.16 \mu \mathrm{gCA} / \mathrm{mgDNA})$ at $104 \mathrm{~h}$ compared to the maximum CA reached in GSPG $(238.37 \mu \mathrm{gCA} / \mathrm{mgDNA})$ at $72 \mathrm{~h}$. 
A.

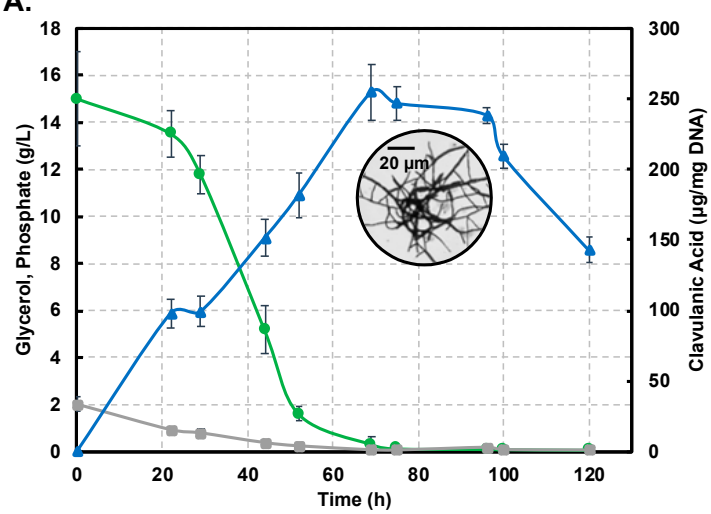

B.

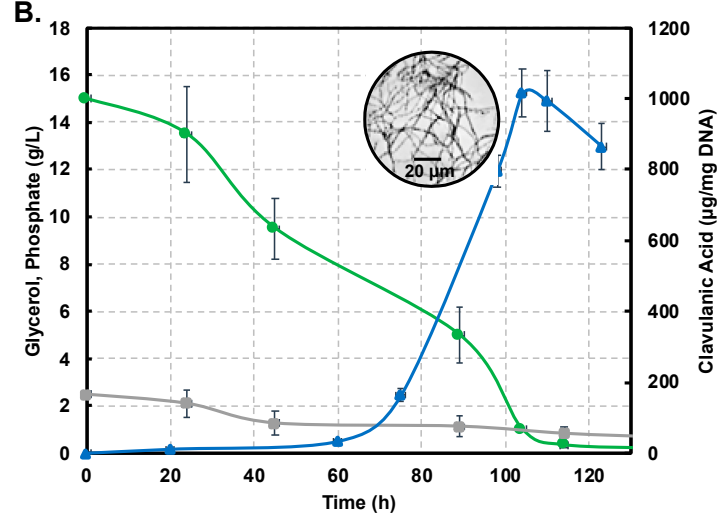

Figure 2. Dynamics of substrate consumption and product biosynthesis in flask cultures of Streptomyces clavuligerus ATCC 27064. (A) Chemically-defined media GSPG. (B). Soybean protein isolate media SB-M. Color code: Clavulanic acid (blue), glycerol (green), phosphate (grey). Note that the secondary axis depicting CA production shows differences in scale, associated with each culture medium.

Differences in strain metabolic response to nutrient perturbation were confirmed not only by CA titers but also by growth measured by the indirect DNA technique. The maximum DNA concentration in biomass produced in the GSPG medium was $97 \mu \mathrm{g}$ DNA/mL at $22 \mathrm{~h}$; in SB-M the higher concentration was reached at $24 \mathrm{~h}(153 \mu \mathrm{g}$ DNA/mL). Circles in Figure 2A,B show the morphology associated with maximum CA concentration in the GSPG and SB-M conditions, respectively. In both conditions, after $75 \mathrm{~h}$ of culture, the disintegration of pellet-like morphology was observed giving rise to disperse hyphae with no branches [22]; the starting point of pellet structure lysis and appearance of non-branched dispersed hyphae was observed, which continued until $120 \mathrm{~h}$. However, in the SB-M condition, the hyphae presented separate compartments, reflective of defective (incomplete) sporulation, and the concomitant decrease in cellular concentration, characteristic of the death phase [23].

\subsection{Identification of Differentially Expressed Genes Between SB-M and GSPG Conditions}

RNA-Seq data analysis revealed a small group of differentially expressed genes; 245 genes were up-regulated in SB-M and 105 were up-regulated in GSPG. The 350 differentially expressed genes constitute $4.73 \%$ of the total genes in the S. clavuligerus genome (Supplementary Table S1). A large percentage of these genes are located in the plasmid pSCL4 in S. clavuligerus ( $29 \%$ and $22 \%$ of total genes in plasmid were up-regulated in SB-M and GSPG, respectively). Differentially expressed genes involved in the main metabolic pathways (primary and secondary metabolism) and some regulated genes of $S$. clavuligerus are listed in Table 1.

Most of the genes in the CA cluster showed a higher expression when S. clavuligerus was cultivated in complex medium; cultivation time was 104 hours for which maximum CA production was achieved and RNA extraction was carried out (see Figure 2B). It was observed that the specific pathway CA regulator, claR (SCLAV_4181), along with the late coding genes N-glycyl-clavaminic acid synthetase gcas (SCLAV_4181) and clavulanate-9-aldehyde reductase cad/car (SCLAV_4190), were up regulated; the latter two are involved in the last step of the CA biosynthetic pathway (see Figure 1). Similarly, the global regulator ccaR (SCLAV_4204) was positively regulated for the SB-M condition. The ceaS2 promoter directs the orchestrated transcription of the early CA biosynthesis genes ceaS2, bls2, pah 2 and cas2, not regulated by claR; ccaR is a controller when it binds to the bidirectional promoters of $c e f D$, $\mathrm{cmcI}$ and lat in the cephamycin C gene cluster, triggering the expression of these operons [24,25]. 
Table 1. Differentially expressed genes involved in primary, secondary metabolism and regulatory genes.

\begin{tabular}{|c|c|c|c|c|}
\hline Gene ID & Protein Name & $\log$ FC & $p$-Value & FDR \\
\hline \multicolumn{5}{|c|}{$\begin{array}{l}\text { Up-regulated genes in SB-M condition } \\
\text { Clavulanic acid biosynthesis }\end{array}$} \\
\hline SCLAV_4194 & Clavaminate synthase 2 (cas2) & 4.388 & $7.210 \times 10^{-9}$ & $1.090 \times 10^{-6}$ \\
\hline SCLAV_4181 & $\mathrm{N}$-glycyl-clavaminic acid synthetase (gcas) & 3.694 & $6.070 \times 10^{-7}$ & $4.890 \times 10^{-5}$ \\
\hline SCLAV_4191 & Transcriptional activator (claR) & 3.393 & $2.960 \times 10^{-5}$ & $1.307 \times 10^{-3}$ \\
\hline SCLAV_4195 & Proclavaminate amidinohydrolase ( $p a h)$ & 3.303 & $5.560 \times 10^{-6}$ & $3.266 \times 10^{-4}$ \\
\hline SCLAV_4196 & Carboxyethyl-arginine beta-lactam-synthase $(b l s)$ & 2.850 & $1.975 \times 10^{-4}$ & $6.227 \times 10^{-3}$ \\
\hline SCLAV_4190 & Clavaldehyde dehydrogenase (car) & 2.739 & $5.920 \times 10^{-5}$ & $2.268 \times 10^{-3}$ \\
\hline SCLAV_4197 & Carboxyethylarginine synthase (ceas) & 2.556 & $1.492 \times 10^{-4}$ & $4.988 \times 10^{-3}$ \\
\hline \multicolumn{5}{|c|}{ Cephamycin $C$ biosynthesis } \\
\hline SCLAV_4206 & Deacetoxycephalosporin C hydroxylase $(c e f F)$ & 5.875 & $1.030 \times 10^{-11}$ & $3.460 \times 10^{-9}$ \\
\hline SCLAV_4208 & Cephalosporin hydroxylase $(\mathrm{cmcI})$ & 5.400 & $6.900 \times 10^{-12}$ & $2.610 \times 10^{-9}$ \\
\hline SCLAV_4211 & Deacetoxycephalosporin C synthetase (DAOC) & 5.104 & $3.480 \times 10^{-11}$ & $1.050 \times 10^{-8}$ \\
\hline SCLAV_4205 & $3^{\prime}$-hydroxymethylcephem-O-carbamoyltransferase $(\mathrm{cmcH})$ & 4.947 & $2.180 \times 10^{-10}$ & $5.280 \times 10^{-8}$ \\
\hline SCLAV_4204 & Positive regulator $(\mathrm{ccaR})$ & 4.226 & $5.870 \times 10^{-9}$ & $9.330 \times 10^{-7}$ \\
\hline SCLAV_4199 & Isopenicillin N synthetase (IPNS) & 4.106 & $1.050 \times 10^{-8}$ & $1.550 \times 10^{-6}$ \\
\hline SCLAV_4201 & L-lysine-epsilon aminotransferase (lat) & 4.015 & $3.810 \times 10^{-7}$ & $3.390 \times 10^{-5}$ \\
\hline SCLAV_4207 & 7-alpha-cephem-methoxylase P8 chain $(\mathrm{cmcJ})$ & 3.274 & $1.060 \times 10^{-5}$ & $5.652 \times 10^{-4}$ \\
\hline SCLAV_4200 & $\begin{array}{l}\text { N-5-amino-5-carboxypentanoyl-L-cysteinyl-D-valine synthase } \\
(p c b A B)\end{array}$ & 3.504 & $5.750 \times 10^{-7}$ & $4.710 \times 10^{-5}$ \\
\hline SCLAV_4210 & Isopenicillin $\mathrm{N}$ epimerase $(\mathrm{cef} D)$ & 3.225 & $5.050 \times 10^{-5}$ & $2.031 \times 10^{-3}$ \\
\hline \multicolumn{5}{|c|}{ Miscellaneous genes } \\
\hline SCLAV_4359 & Neutral zinc metalloprotease & 8.313 & $1.630 \times 10^{-19}$ & $9.840 \times 10^{-16}$ \\
\hline SCLAV_4112 & Extracellular small neutral protease & 6.589 & $6.580 \times 10^{-14}$ & $6.640 \times 10^{-11}$ \\
\hline SCLAV_4455 & Beta-lactamase inhibitory protein & 5.316 & $5.960 \times 10^{-10}$ & $1.240 \times 10^{-7}$ \\
\hline SCLAV_4202 & BLP (Beta-Lactamase Inhibitory Protein) & 5.227 & $2.420 \times 10^{-10}$ & $5.640 \times 10^{-8}$ \\
\hline SCLAV_p1319 & Putative transcriptional regulator $\mathrm{AraC}$ family & 5.113 & $2.340 \times 10^{-9}$ & $4.080 \times 10^{-7}$ \\
\hline SCLAV_2754 & RNA polymerase sigma factor & 4.943 & $5.760 \times 10^{-5}$ & $2.247 \times 10^{-3}$ \\
\hline SCLAV_p1007 & Beta-lactamase domain protein & 4.755 & $2.820 \times 10^{-9}$ & $4.740 \times 10^{-7}$ \\
\hline SCLAV_4723 & Beta-lactamase inhibitory protein & 4.694 & $1.720 \times 10^{-8}$ & $2.480 \times 10^{-6}$ \\
\hline SCLAV_p0769 & Sigma factor, $\sigma^{70}$ type, group 4 & 4.637 & $2.243 \times 10^{-4}$ & $6.856 \times 10^{-3}$ \\
\hline SCLAV_3577 & NADH-quinone oxidoreductase subunit $\mathrm{N}$ & 4.603 & $6.800 \times 10^{-6}$ & $7.350 \times 10^{-6}$ \\
\hline SCLAV_p1321 & LysR family transcriptional regulator & 4.238 & $1.840 \times 10^{-7}$ & $1.790 \times 10^{-5}$ \\
\hline SCLAV_4189 & Cytochrome P450-SU2 (cyp) & 3.523 & $5.630 \times 10^{-6}$ & $3.277 \times 10^{-4}$ \\
\hline SCLAV_4464 & Transcriptional regulator, LuxR family & 3.086 & $4.304 \times 10^{-4}$ & $1.160 \times 10^{-2}$ \\
\hline SCLAV_1957 & AraC family transcriptional regulator $(a d p A)$ & 2.835 & $3.971 \times 10^{-4}$ & $1.108 \times 10^{-2}$ \\
\hline \multicolumn{5}{|c|}{ Carbon metabolism } \\
\hline SCLAV_5677 & Aldehyde dehydrogenase & 5.151 & $9.470 \times 10^{-12}$ & $3.370 \times 10^{-9}$ \\
\hline SCLAV_0665 & Acyl-CoA dehydrogenase & 2.943 & $2.290 \times 10^{-4}$ & $6.964 \times 10^{-3}$ \\
\hline SCLAV_3742 & Malate dehydrogenase & 2.146 & $1.345 \times 10^{-3}$ & $2.800 \times 10^{-2}$ \\
\hline SCLAV_1401 & Pyruvate dehydrogenase E1 component & 2.107 & $1.630 \times 10^{-3}$ & $3.202 \times 10^{-2}$ \\
\hline \multicolumn{5}{|c|}{ Nitrogen metabolism } \\
\hline SCLAV_2388 & $\mathrm{N}$-acetylglutamate synthase & 3.786 & $2.454 \times 10^{-3}$ & $4.380 \times 10^{-2}$ \\
\hline SCLAV_0800 & Arginine biosynthesis bifunctional protein $(\operatorname{argJ})$ & 3.184 & $1.391 \times 10^{-3}$ & $2.844 \times 10^{-2}$ \\
\hline SCLAV_0796 & Argininosuccinate synthase & 3.171 & $8.450 \times 10^{-6}$ & $4.685 \times 10^{-4}$ \\
\hline SCLAV_4534 & Ammonium transporter & 2.896 & $2.420 \times 10^{-5}$ & $1.087 \times 10^{-3}$ \\
\hline SCLAV_0798 & Acetylornithine aminotransferase (oat2) & 2.582 & $5.623 \times 10^{-4}$ & $1.418 \times 10^{-2}$ \\
\hline SCLAV_0799 & Acetylglutamate kinase & 2.553 & $1.598 \times 10^{-3}$ & $3.160 \times 10^{-2}$ \\
\hline \multicolumn{5}{|c|}{ Down-regulated genes in GSPG } \\
\hline SCLAV_5442 & Putative transcriptional regulator & -6.728 & $2.427 \times 10^{-3}$ & $4.380 \times 10^{-2}$ \\
\hline SCLAV_1087 & Putative penicillin-binding protein & -4.02 & $1.310 \times 10^{-4}$ & $4.536 \times 10^{-3}$ \\
\hline SCLAV_2302 & TetR-family transcriptional regulator & -3.962 & $1.670 \times 10^{-4}$ & $5.440 \times 10^{-3}$ \\
\hline SCLAV_4124 & Putative PadR-like family transcriptional regulator & -3.839 & $1.910 \times 10^{-5}$ & $9.100 \times 10^{-4}$ \\
\hline SCLAV_5441 & Pyruvate phosphate dikinase & -3.701 & $5.920 \times 10^{-4}$ & $1.469 \times 10^{-2}$ \\
\hline SCLAV_3293 & RNA polymerase ECF-subfamily sigma factor & -3.549 & $1.024 \times 10^{-3}$ & $2.237 \times 10^{-2}$ \\
\hline SCLAV_3942 & Penicillin-binding protein & -3.525 & $4.230 \times 10^{-4}$ & $1.155 \times 10^{-2}$ \\
\hline SCLAV_1943 & Acetyl/propionyl CoA carboxylase & -3.410 & $2.440 \times 10^{-5}$ & $1.086 \times 10^{-3}$ \\
\hline SCLAV_3597 & Two-component system sensor kinase & -3.380 & $2.453 \times 10^{-3}$ & $4.380 \times 10^{-2}$ \\
\hline SCLAV_p0423 & Transcriptional regulator, XRE family protein & -3.266 & $1.760 \times 10^{-5}$ & $8.660 \times 10^{-4}$ \\
\hline SCLAV_5443 & Transcriptional regulator & -2.982 & $2.360 \times 10^{-4}$ & $7.104 \times 10^{-3}$ \\
\hline SCLAV_p1581 & Transcriptional regulator, BadM/Rrf2 family & -2.875 & $4.930 \times 10^{-4}$ & $1.272 \times 10^{-2}$ \\
\hline SCLAV_0603 & Putative PadR-like family transcriptional regulator & -2.718 & $1.960 \times 10^{-4}$ & $6.213 \mathrm{v} 10^{-3}$ \\
\hline SCLAV_2046 & 4-hydroxyphenylpyruvate dioxygenase & -2.707 & $1.520 \times 10^{-4}$ & $5.053 \times 10^{-3}$ \\
\hline SCLAV_2979 & Putative dihydrolipoamide acyltransferase & -2.679 & $8.140 \times 10^{-4}$ & $1.873 \times 10^{-2}$ \\
\hline SCLAV_2974 & 3-hydroxybutyryl-CoA dehydrogenase & -2.659 & $4.310 \times 10^{-4}$ & $1.160 \times 10^{-2}$ \\
\hline SCLAV_4588 & Aldehyde dehydrogenase & -2.492 & $2.513 \times 10^{-3}$ & $4.447 \times 10^{-2}$ \\
\hline SCLAV_4386 & Putative transcriptional regulator & -2.254 & $9.460 \times 10^{-4}$ & $2.113 \times 10^{-2}$ \\
\hline
\end{tabular}

Our results showed differential expression of malate dehydrogenase $m$ dh and SCLAV_4122 in SB-M, thus contributing to the formation of oxaloacetate from malate and/or acetyl-CoA; both oxaloacetate and acetyl-CoA play an important role in the synthesis of amino acid anabolic precursors e.g., aspartate 
and lysine, for CA and CephC biosynthesis, respectively. Likewise, the formation of fumarate through succinate dehydrogenase (SCLAV_3769 and SCLAV_3770) might be an important precursor of argininosuccinate via $\operatorname{argH}$ (argininosuccinate lyase), whose expression also increased in SB-M. TCA-cycle-associated genes e.g., acyl-CoA dehydrogenase (SCLAV_0665), malate dehydrogenase (SCLAV_3742) and central metabolism-associated genes e.g., those coding for pyruvate dehydrogenase (SCLAV_1401) and aldehyde dehydrogenase (SCLAV_5677), were differentially expressed.

Arginine metabolism has also been extensively studied in S. clavuligerus since, together with GAP, they are direct precursors of CA. In our results, oat2, located in the CA cluster, along with argJ, had a higher expression in SB-M, whereas oat1 expression was favored in GSPG. oat1 and oat2 are ornithine acetyltransferases, which transfer an acetyl group from $\mathrm{N}$-acetylornithine to glutamate, increasing the pool of arginine via glutamate. Also, a differential expression of the genes associated with nitrogen transport was observed e.g., oligopeptide permeases (SCLAV_4407 and 4408), peptide transporters (SCLAV_p1156), the PII regulatory protein for nitrogen metabolism (SCLAV_4535), the ammonium transporter (SCLAV_4534) along with glutamine synthase (SCLAV0834) and N-acetylglutamate synthase (NAGS) (SCLAV_2388); the latter is involved in the metabolism of arginine and the urea cycle inter-connection. oat1, located in the clavam $5 \mathrm{~S}$ cluster, has been reported as non-essential for CA (or clavams) production, but its role in some unidentified steps in CA-5S clavam biosynthetic pathway cannot be ruled out $[26,27]$. Furthermore, several genes related to growth or primary metabolism were up-regulated in the rich medium, e.g., 11 genes for ribosomal proteins and the EF-Tu elongation factor, 12 genes for the subunits of the NADH quinone reductase, genes for ATP synthases and cytochrome oxidases or 5 genes for branched amino acids SCLAV_1197 to 1201.

Correspondingly, acetylglutamate kinase, $\arg B, \mathrm{~N}$-acetyl-gamma-glutamyl-phosphate reductase, $\arg C(2.52 \mathrm{FC})$, acetylornithine aminotransferase, $\arg D(3.0 \mathrm{FC})$, arginine biosynthesis bifunctional protein and argininosuccinate synthase (SCLAV_0799) showed higher expression in the SB-M condition. Glutamate is an important amino acid precursor in CA biosynthesis [28,29]; glutamate conversion to arginine, reaction mediated by NAGS, involves ornithine as intermediate metabolite [28].

Further, for GSPG, most down-regulated genes are associated with cell maintenance and transport, as expected for a limited medium with low antibiotic concentrations. Down-regulated are three genes for alkaline peptidases, 4 genes for phenylacetic acid degradation and 4 genes for a putative lantibiotic (see Supplementary Table S1). Metabolism of phenylacetic acid has been described in other species of Streptomyces and phenylacetic acid has shown antifungal activities; thus, such activities cannot be ruled out for the case of $S$. clavuligerus [30]. Likewise, bacteriocins, peptide antibiotics produced by bacteria, e.g., lantibiotics, represent a rich repository that can yield a large number of valuable novel antimicrobials [31].

\subsection{Validation of Differentially Expressed Genes by Quantitative qRT-PCR}

Figure 3 shows the relative expression of selected genes by taking the GSPG condition as control and SB-M as experimental condition so as to establish changes in gene expression when S. clavuligerus is grown under favorable conditions. Correlation analyses between RNA-seq and RT-qPCR data were performed using linear regression analysis (Pearson correlation). The results found by qRT-PCR for the selected genes are in concordance with those found by RNA-Seq; an acceptable correlation was obtained indicating the reliability of the RNA-seq analysis. Although qRT-PCR was used to verify expression differences, no protein analyses were performed to confirm that the differential expression was observed at the protein level. Some previous studies have shown poor correlation between RNA-Seq and proteomics analysis; the two approaches are best used in combination [32]. A good correlation $\left(R^{2}=0.51\right.$ to 0.98$)$, considering mRNA expression levels and the protein levels, has been conveyed in the Streptomyces genus, using a proteomic analysis [33,34]. 


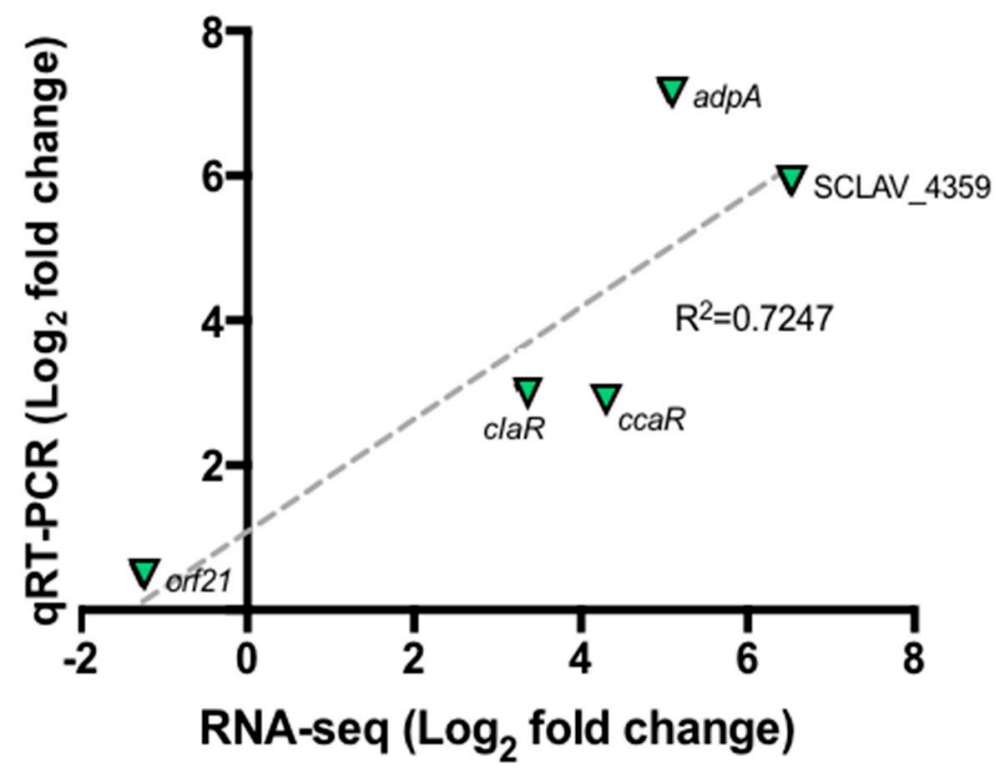

Figure 3. Quantitative real time PCR for selected genes orf21, ccaR, adpA and SCLAV_4359. Correlation between RNA-Seq experiment and qRT-PCR. The dashed gray line represents the least squares adjustment for the data points shown.

\subsection{GO Term Enrichment Analysis}

Genes up- and down-regulated were subjected to functional enrichment analysis [35]. Figure 4 shows the significantly enriched Gene Ontology (GO) terms associated with up-regulated (more highly expressed in SB-M medium) (red) and down-regulated (more highly expressed in GSPG medium) genes (blue). The parent-child GO term analysis detected a total of $123 \mathrm{GO}$ terms significantly overrepresented for the SB-condition and 46 for GSPG, both with a $p$-value $<0.01$; from these, $36 \%$ refer to biological processes.

The up-regulated genes, which include genes involved in CA and CephC metabolism, were found to be related to antibiotic biosynthetic processes (GO:0017000) and drug metabolic processes (GO:0017144). Moreover, oxidation-reduction (GO: 0055114) was significantly enriched, in keeping with oxidoreductase acting on oxidative phosphorylation and control of oxidative stress. The complex medium also favors protein degradation, proteolysis (GO:0006508) and amino acid metabolism, mainly proline related-processes; proline biosynthetic process (GO:0006561) and proline metabolic process (GO:0006560) and branched amino acid transport (GO:0015803).

In addition, due to the limited-nutrient content in GSPG, the most relevant processes associated with down-regulated genes were synthesis of RNA, RNA processing (GO:0006396), response to stimulus, cellular response to chemical stimulus (GO:0070887) and negative regulation of proteolysis; secondary metabolism related pathways were not significantly overrepresented. 


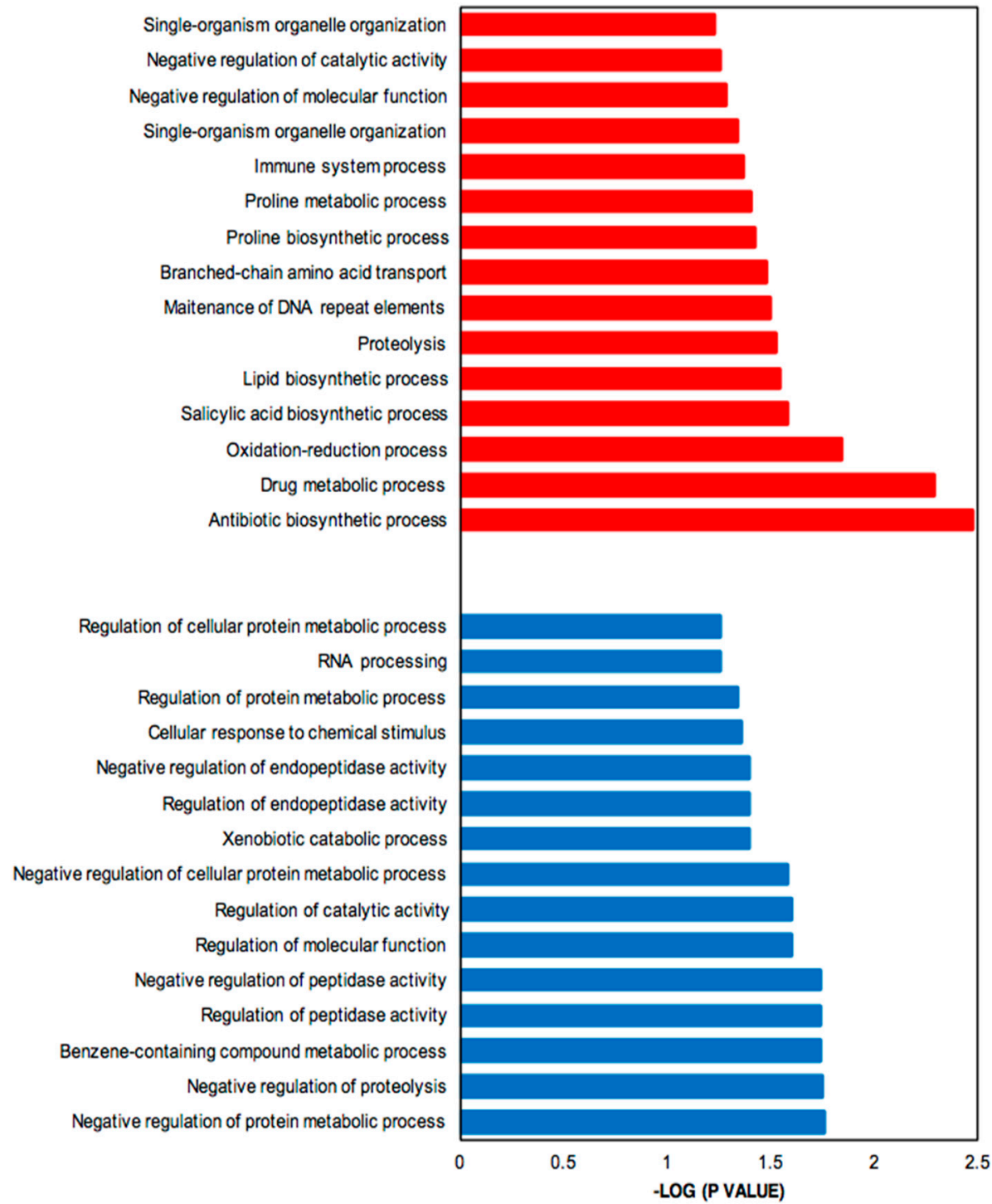

Figure 4. Bar plot for the $-\log 10$ of the $p$-value of selected GO terms (biological process). The upand down-regulated genes (q-value (FDR) threshold) were subjected to gene ontology analysis using Ontologizer 2.0. The enriched biological processes were plotted. Red bar, enriched GO terms regulated by up-regulated genes; blue bar, enriched GO terms regulated by down-regulated genes.

\section{Discussion}

Transcriptome analysis contributes to the identification of transcript abundance during cellular development and environmental perturbations. It may also contribute to elucidating unknown regulatory patterns. Some transcriptomic studies of Streptomyces strains have described gene expression using different mutants [25,36-39]. In this work, a gene expression analysis of S. clavuligerus, grown under different nutrient conditions, was performed. This is the first study focused on analyzing the nutritional effect on $S$. clavuligerus metabolism using a complex soybean-based media, widely used for CA production but as yet unexplored at the level of gene-expression.

Overall, it is clear that the soybean-based media favors CA biosynthesis due to the high content of amino acids known to be precursors of CA biosynthesis $[6,12,20,40]$. CA, as a secondary metabolite, is non-essential for growth; a reduction in the growth rate was observed past $48 \mathrm{~h}$ of cultivation (Figure 2), in both the GSPG and SB- media, which coincides with the onset of secondary metabolism $[2,13]$. Trends for the production profiles are in agreement with those found in related studies $[6,12,20,21]$. 
Likewise, the presence of phosphate, at the end, remained in the margins of restrictive concentration thus favoring antibiotic biosynthesis [21].

Interestingly, we observed that decrease in growth rate, complemented by depletion of the carbon source, induces the necessary nutritional stress for triggering CA biosynthesis. The maximum amount of CA in the SB-M condition was observed at a later time of culture, accompanied by unbranched (dispersed) hyphal morphology (box in Figure 2B), and characterized by separate compartments, not observed in GSPG; this might be the result of programmed cell death processes [41]. The biological function of Streptomyces programmed cell death remains unclear although it was reported as a mechanism involved in nutrient generation from primary mycelium (MI) consumption, a kind of cannibalism, by the aerial/sporulating mycelium (secondary mycelium MII). According to Bushell [42], the frequency of branching of the vegetative hyphae is strongly dependent on growth conditions, whereby nutrient-rich conditions as SB-M favors branching while, under nutrient-depleted (GSPG) conditions, branching is reduced and growth is dictated by tip extension, thus favoring the formation of the so-called searching hyphae [43]. Moreover, an increase in culture viscosity was observed throughout the SB-M culture experiments; Kim and Kim (2004) suggested that this could be associated with the high density of extracellular polymers and insoluble substrates [23,44].

According to the transcriptome analysis, up-regulated genes in the SB-M condition were involved mostly in regulatory mechanisms for secondary metabolism, and biosynthetic genes for antibiotic production. Consequently, CA and, speculatively, cephamycin C, were accumulated. The transcriptional regulators $C c a R$ and $C l a R$ have direct and proven influence on CA biosynthetic genes, showing a greater differential expression. The protein product of the $c c a R$ gene, located in the cephamycin C gene cluster, is a positive regulator which encodes for both CA and CephC production in S. clavuligerus. ccaR controls antibiotic biosynthesis by regulating the transcription of biosynthetic genes, e.g., the ceaS2 promoter, which encodes for the CA pathway intermediary carboxyethyl-arginine (Figure 1) [45].

claR, a LysR transcriptional regulator type located in the CA gene cluster, positively regulates the expression of late genes involved in the clavaminic acid conversion to CA [3]; the biosynthetic and regulatory genes showed higher expression profiles when S. clavuligerus was grown in the SB-M medium, which favors CA production. Interestingly, regarding the regulation associated with AraC family regulators, the two genes encoding products of this family (SCLAV_1957 and SCLAV_p1319) were up-regulated along with the transcriptional regulator SCLAV_p0773, all located in the plasmid, which might suggest a complex extrachromosomal regulation in antibiotic production. Although the $S$. clavuligerus pSCL4 mega-plasmid does not contain essential genes for primary metabolism, it is densely packed with a large number of clusters for secondary metabolite production, including B-lactam antibiotics [46]. In this study, the clavam gene cluster and cas1 were not significantly expressed; this is consistent with CA production in SB-M and the positive regulation of the paralogous gene, cas2. It might indicate that, for this experimental condition, the production of $\mathrm{CA}$ and cephamycin $\mathrm{C}$ was benefited, rather than the production of clavams.

An alternative regulation mode that commonly controls antibiotic production in Streptomyces involves sigma factors and related mechanisms, e.g., anti-sigma and anti-anti-sigma factors [47]. Transcriptional regulation by sigma factors is common in bacteria such as Bacillus sp. for the control of sporulation and other responses associated with stress. The genome of $S$. clavuligerus presents 75 sigma factors, which suggest a sigma factor-based regulation. The RNA polymerase sigma factor (SCLAV_2754) and the sigma factor $\sigma^{70}$ type (SCLAV_p0769) are proposed to be involved in the coordination of transcriptional regulation in response to environmental factors such as nutritional, osmotic and oxidative stress; apparently, they are also associated with development (differentiation), yet currently there is no certainty over their specific function [47].

Furthermore, the sigma factor orf 21 , reported as a regulatory gene, does not show significant changes in expression when CA synthesis is carried out (Figure 3). It is suggested that the orf21 expression could be influenced by environmental factors, e.g., at the onset of nutrient depletion. 
In addition, the RNA polymerase containing the primary factor that initiates the transcription of a large number of genes, commonly expressed during the exponential growth phase and at $104 \mathrm{~h}$, is already in its latency phase; therefore, the transcription of certain genes has already ceased [48,49]. Culture conditions along with the sampling time, might explain the results. Further gene expression profiling studies at different cultivation times would contribute to clarify this uncertainty.

In addition to sigma factors, the Lux-R (LTR) or Lys-R regulators represent the most abundant regulators in prokaryotes; these regulate various groups of genes that, for the case of Streptomyces, involve antibiotic synthesis [50]. The LAL family, a poorly studied group of transcriptional regulators, some of which have been identified in antibiotic clusters and other secondary metabolites of actinomycetes, have been considered path-specific regulators [51]. In this study, LuxR family transcriptional regulator (SCLAV_4464), located on the chromosome, seems to be favored (3.086 LogFC) for the high antibiotic production condition; the same was observed for the Lys-R family transcriptional regulator SCLAV_p1321 (4.231 LogFC), located in the plasmid, close to the cephamycin C cluster. However, there is no experimental evidence about potential interactions between these regulators and the antibiotic produced by $S$. clavuligerus.

Moreover, the regulatory protein AdpA (SCLAV_1957) has been extensively studied in Streptomyces griseus and S. coelicolor species; it appears to regulate sporulation, morphogenesis and antibiotics production [52]. The assays performed by Lopéz-Garcia et al., 2010, using S. clavuligerus in relation to $A d p A$, showed that the deletion of the regulator resulted in a low formation of aerial mycelium and the absence of sporulation itself. This apparently leads to a $10 \%$ decrease in the concentration of CA compared to the control strain, as a result of low expression of the regulatory genes ccaR and claR (7- and 4-fold, respectively) [53]. For the conditions assessed in this work, ccaR, claR and adpA were significantly up-regulated (4.2, 3.39 and 2.83-fold respectively) coinciding with high CA concentration.

The expression of $a d p A$ exhibited a similar behavior to that found for $c c a R$ and $c l a R$. The higher expression in $c l a R$ relative to $c c a R$ could be explained if one considers that the $a d p A$ regulatory effect on these regulators is more noticeable in relation to CA synthesis than that with cephamycin C. Our results agree with this observation; regulatory cascades for both CA and cephamycin biosynthesis, are apparently different since the expression of the CA cluster showed a slightly higher expression compared to that of CephC [49]. Moreover, soy proteins present in the SB-M medium are a major nitrogen source; soy protein assimilation is mediated by extracellular proteases produced by Streptomyces sp. However, when the amino acid source is scarce at the end of the exponential growth phase, protease induction guarantees cell development. Different metalloproteases have been identified in species such as Streptomyces lividans, Streptomyces cacoi, Streptomyces fradiae and Streptomyces griseus, playing a fundamental role in mycelial growth and cell viability [52]. In Streptomyces griseus, it was found that the adpA regulatory cascade, besides controlling antibiotic production of streptomycin (strR regulator), was associated with metalloendopeptidase enzyme synthesis $(\operatorname{sgm} A)$ to cannibalize the primary mycelium (MI) [54]. sgmA encodes a zinc-dependent metalloprotease; its deletion causes an aerial mycelium formation delay. In deletion mutants of $a d p A$, $\operatorname{sgm} A$ transcripts were not detected, indicating that $A d p A$ serves as a transcriptional activator of $\operatorname{sgm} A$ [54]. Further, since $A d p A$ acts as a switch for aerial mycelium formation, it may also be involved in hydrolytic enzyme expression (lipases, nucleases and proteases) whose action allows cellular differentiation by degradation of cytoplasmic contents, causing hyphal dispersion, followed by secondary mycelium formation and ending with the cellular death phase [37].

As expected, our results suggest that the soy-based culture medium components induce the formation of extracellular hydrolases and proteases in S. clavuligerus (Table 1), forcing the bacterium to further degrade the protein during growth, thus ensuring a constant supply of nutrients, essential for primary and secondary metabolism. Within the up-regulated genes we found two metalloproteases (SCLAV_4112 and SCLAV_4359), which are strongly influenced by the nitrogen source. It is known that, in batch cultures, the production of extracellular proteases occurs at low or intermediate growth rates; yet, when the bacterium presents high growth rates the post-exponential phase is delayed, 
suggesting that formation of proteases can be induced by the decrease of amino acids present in the medium [55]. In the genus Bacillus, the formation of protease and sporulation are often triggered by a nutritional deficit, and by genes that have pleiotropic effects on such processes [56]. Nonetheless, the relationship of proteases and the initiation of morphological differentiation in Streptomyces species other than S. griseus has not been well established [57].

Some authors have suggested that the adpA regulator found in S. clavuligerus is involved both in antibiotic production and morphological differentiation, similarly to $S$. griseus [53]. The zinc-dependent metalloprotease, SCLAV_4359, was also found overexpressed in the transcriptional study [36]; the higher expression of the metalloprotease SCLAV_4359 at $104 \mathrm{~h}$ at the onset of cell lysis, might suggest that synthesis of this hydrolytic enzyme may be involved in both apoptosis and morphological differentiation, similar to sgmA in S. griseus.

The $S$. clavuligerus metalloprotease has 681 amino acids and its active site is located in the same region of SgmA (351 and 370, respectively); the similarity between SCLAV_4359 and sgmA found by alignment of their amino acid sequences using Blastp [58] was 79\%. Until now, studies on proteases in S. clavuligerus have been limited compared to other streptomycetes species; it is worthy to consider a further study on SCLAV_4359 as a possible hydrolytic enzyme and its relationship with morphological differentiation. Recently, Álvarez-Álvarez et al., (2014) using a microarray technique, showed that SCLAV_4359 had high expression at the end of stationary phase in a ccaR deletion mutant ( $\Delta c c a r:: t s r:)$ compared with the reference strain (ATCC 27064); although a logical decrease of CA was evidenced, the SCLAV_4359 expression value was associated neither with morphological development nor with global regulation [36].

Regarding the SCLAV_4359 gene (neutral zinc metalloprotease), it was possible to establish that CA synthesis occurred under conditions of stress induced by exhaustion of the amino acid content, which indicates that nutritional stress, both by nitrogen and carbon, might orchestrate the synthesis of antibiotics by secondary metabolism induction. The potential biological interaction between adpA, encoding a regulator, and a neutral-zinc metalloprotease encoding SCLAV_4359, both up-regulated in the SB-M condition, has not been elucidated yet. This identified novel relationship might lead to new insights about metabolic and/or regulatory mechanisms that associate morphological development and antibiotic biosynthesis. These findings strengthen the usefulness and significance of transcriptome analyses in cell metabolic and regulatory studies.

Finally, down-regulated genes were grouped into those necessary for cell maintenance and membrane transport. In this respect, the penicillin-binding proteins PBP (SCLAV_3942 and SCLAV_1087, both located in the chromosome) were differentially expressed; recent reports have shown that, in S. clavuligerus, these genes can be expressed during different developmental stages, mainly for peptidoglycan biosynthesis. It is known that there is a possible interference of peptidoglycan synthesis when B-lactam compounds are produced at high concentrations. However, for the case of the GSPG, CA levels are not that high compared with those observed in SB-M [21]. Regarding regulatory genes, the TetR-family transcriptional regulator, encoded by SCLAV_2302, is a protein involved in the transcriptional control of multidrug efflux pumps, antibiotic biosynthetic pathways, response to osmotic stress and toxic chemicals, catabolic pathway control and differentiation processes [59]. Other transcriptional regulators, encoded by SCLAV_4386, SCLAV_5443, SCLAV_4386, SCLAV_5443, SCLAV_p0423, SCLAV_p1581, and SCLAV_5442, have no evidence of specific regulation.

In conclusion, in this work, it was possible to identify clear differences in gene expression when S. clavuligerus is exposed to favorable and unfavorable nutrient conditions. Considering the differences in S. clavuligerus morphology during its life cycle, and its metabolic response associated with the environment and nutrient content, found in this work, it is worthy to further study the dynamics of gene expression during these extreme conditions so as to contribute to the understanding of how environmental perturbations may affect genes related to morphological differentiation and secondary metabolism; these topics have not been studied in depth in S. clavuligerus, using a systems approach [60]. 


\section{Materials and Methods}

\subsection{Bacterial Strain and Cultivation}

S. clavuligerus ATCC 27064 was used throughout this study. Mycelium was obtained following the standard protocol for Streptomyces sp. [61], and was stored in $1.5 \mathrm{~mL}$ Eppendorf tubes with a $20 \%$ glycerol sterile solution at $-80^{\circ} \mathrm{C}$. The seed medium consisted of $50 \mathrm{~mL}$ TSB medium $\left(30 \mathrm{~g} \cdot \mathrm{L}^{-1} ; \mathrm{pH} 7.0\right)$ in $250 \mathrm{~mL}$ baffled Erlenmeyer flasks inoculated with mycelium stock and incubated at $28^{\circ} \mathrm{C}$ for $36 \mathrm{~h}$ at $220 \mathrm{rpm}$. The following culture media were used: GSPG medium composed of (g/L): glycerol, 15; sucrose, 20; glutamic acid, 1.5; L-proline, 2.5; $\mathrm{NaCl}, 5.0 ; \mathrm{K}_{2} \mathrm{HPO}_{4}, 2.0 ; \mathrm{MgSO}_{4} \cdot 7 \mathrm{H}_{2} \mathrm{O}, 1.0 ; \mathrm{CaCl}_{2}$, $0.4 ; \mathrm{MnCl}_{2} \cdot 4 \mathrm{H}_{2} \mathrm{O}, 0.1 ; \mathrm{FeCl}_{3} \cdot 6 \mathrm{H}_{2} \mathrm{O}, 0.1 ; \mathrm{ZnCl}_{2}, 0.05 ;$ MOPS (3-(N-morpholino) propanesulfonic acid), 20.9 [62]. The favorable nutrient isolated soybean-based medium (SB-M) (Bell Chem International S.A), composed of (g/L): glycerol, 15.0; soy protein isolate, 10.0; malt extract, 10.0; yeast extract, 1.0; $\mathrm{K}_{2} \mathrm{HPO}_{4}, 2.5 ; \mathrm{MgSO}_{4} \cdot 7 \mathrm{H}_{2} \mathrm{O}, 0.75 ; \mathrm{MnCl}_{2} \cdot 4 \mathrm{H}_{2} \mathrm{O}, 0.001 ; \mathrm{FeSO}_{4} \cdot 7 \mathrm{H}_{2} \mathrm{O}, 0.001 ; \mathrm{ZnSO}_{4} \cdot 7 \mathrm{H}_{2} \mathrm{O}, 0.001 ; \mathrm{MOPS}$, 21.0 [21]. All cultures were performed in 250-baffled ( 4 baffles) Erlenmeyer flasks containing $50 \mathrm{~mL}$ of medium. Flasks were inoculated with seed medium $(10 \% \mathrm{v} / \mathrm{v})$ as described above, at an average initial biomass concentration of $0.09 \pm 0.015 \mathrm{~g} / \mathrm{L}$. Cultures were incubated at $220 \mathrm{rpm}$ and $28{ }^{\circ} \mathrm{C}$ for $120 \mathrm{~h}$.

\subsection{Analytical Techniques}

Culture samples were centrifuged at $14,000 \times g$ for $10 \mathrm{~min}$ at $4{ }^{\circ} \mathrm{C}$, and filtered through a $0.22 \mu \mathrm{m}$ membrane. CA was determined by HPLC Agilent 1200 (Agilent Technologies, Waldbrom, Germany) equipped with a Diode Array Detector (Agilent Technologies, Palo Alto, CA, USA) at 312 nm, using a reverse phase ZORBAX Eclipse XDB-C $18(4.6 \times 150 \mathrm{~mm}, 18 \mu \mathrm{m}$ Agilent Technologies, Palo Alto, CA, USA) column; $96 \% \mathrm{v} / \mathrm{v} \mathrm{KH}_{2} \mathrm{PO}_{4}(50 \mathrm{mM}, \mathrm{pH} 3,2)$ and a $6 \% \mathrm{v} / \mathrm{v}$ methanol was used as mobile phase at $1 \mathrm{~mL} / \mathrm{min}$. CA was imidazole-derivatized at a ratio 1:3; the reaction was kept at $30{ }^{\circ} \mathrm{C}$ for $30 \mathrm{~min}$ [63]. Phosphate quantification was carried out as molybdivanadophosphoric acid by a colorimetric technique, as described elsewhere [64]. Glycerol concentration was determined based on acidic periodate oxidation of alditols to produce formaldehyde, in the presence of L-rhamnose, and the addition of the Nash reagent; it was spectrophotometrically quantified at $412 \mathrm{~nm}$, as described elsewhere [65]. Due to the presence of suspended particles, mainly in SB-M, the Burton's method, based on DNA determination, was employed for cell growth quantification [66]. The DNA concentration was determined by the diphenylamine reaction: in this assay, DNA was first hydrolyzed under hot acidic conditions, and the deoxyriboses were further oxidized into 5-hydroxy-4-oxopentanals, which then were dimerized and condensed with diphenylamine; the final products were spectrophotometrically detected at $595 \mathrm{~nm}[66]$.

\subsection{RNA Extraction, Library Preparation, and Sequencing}

S. clavuligerus was cultured in the GSPG- and SB- culture media as previously described. In order to study the transcripts associated with enzymes related to antibiotic synthesis and the overall transcriptome response to nutrient perturbations, CA concentration, nutrient consumption and growth were quantified over time. RNA extraction was performed during idiophase at $104 \mathrm{~h}$ when CA concentration was the highest for the conditions evaluated. Samples were centrifuged at $10,000 \times g$ for $15 \mathrm{~min}$, and cell pellets were immediately frozen using liquid nitrogen, then stored at $-80{ }^{\circ} \mathrm{C}$ for subsequent RNA isolation. Total RNA was isolated using Trizol@(Invitrogen $囚)$, following the manufacturer's protocols. All RNA preparations were treated with RNase-free DNase (Promegaß) to eliminate genomic DNA contamination; the purity, integrity and concentration of RNA was determined using a Bioanalyzer 2100 (Agilent Technologies®). The total RNA remaining in the supernatant was recovered by ethanol precipitation and quantified by a Bioanalyzer 2100. Only samples with high-quality RNA (RNA integrity number $\geq 7.0$ ) were used in the following mRNA library preparation for sequencing. A cDNA library was constructed and sequenced by Illumina 
Hiseq $^{\mathrm{TM}} 2000$ (Illumina, San Diego, CA, USA) using the standard Illumina RNA-Seq protocol with a read length of $2 \times 100$ bases [67].

\subsection{Reads Mapping to Reference Genome and Differential Expression Analysis}

The raw sequencing reads were trimmed for low-quality ends by removing adapter sequences and ambiguous nucleotides, using the software FastQC (version 0.11.3) [68]. All sequencing reads with quality scores (phred score) less than 30 (medium quality sequence) and read length below $75 \mathrm{bp}$ (short read length sequence) were excluded using the FastX Toolkit (version 0.0.13) [69]. The remaining high-quality reads were used in subsequent alignments.

The RNA-Seq paired-end reads were mapped using Bowtie2 [70] against the Streptomyces clavuligerus ATCC27064 reference genome sequence, available in Genbank (accession number NZ_CM000913.1 and NZ_CM000914.1, chromosome and megaplasmid, respectively) [46]. Prior to alignment, the read counts for each gene were extracted using the htseq-count command of HTseq (version 0.6.1) [71] based on all annotated genomic features of the S. clavuligerus reference genome (NCBI genome assembly id: 280082) and aligned reads. The total mapped reads and overall alignment rates were $23,186,844(99.90 \%)$ and 19,580,887 (99.87\%) in SB-M and GSPG, respectively.

The EdgeR package (version 3.22.3) was used to identify differential gene expression [72], including false discovery rate (FDR) calculations. The total mapped reads for each transcript from HTseq were transformed to cpm (counts-per-million read); analyses performed in this study used a $\log _{2}$ scale of the data; pseudo-counts of 1 were added to the dataset. The filtering was made using cpm as criteria and normalized using the implemented calcNormFactors function within EdgeR to find a set of scaling factors for library sizes that minimize the log-fold changes (log FC) between the samples for most genes. Due to the treatment conditions and the typical variations, a negative binomial model was used so as to establish the biological coefficient of variation (BCV); that is, the relative abundance of each gene among RNA samples, associated with biological causes and measurement errors, intrinsic to the sequencing technology [72]. Once the negative binomial model was fitted and the dispersion determined, we proceeded with the extacttest procedure for determining differential expression; only values with an associated $p<0.05$ and FDR $\leq 0.05$ were considered to be significant.

\subsection{RNA-seq Raw Sequencing Data Accession Information}

The RNA-seq raw sequencing data of $S$. clavuligerus was deposited in the SRA database of NCBI with accession number SAMN11046362.

\subsection{Validation of Differentially Expressed Genes by Quantitative qRT-PCR}

RNA templates for qRT-PCR were isolated using the UltraClean $®$ Microbial RNA Isolation Kit (MO BIO Laboratories, Inc. CA). The selected genes were: The regulatory protein AdpA (SCLAV_1957), the sigma factor orf21, present in the CA biosynthesis cluster, the claR pathway-specific regulator, and the ccaR transcriptional regulator of cephamycin C and CA. Also, for validating differential expression, the metalloprotease SCLAV_4359 was included. As a housekeeping gene, the chromosomal gene $h r d B$ was chosen as an internal control and referenced as a constitutively expressed gene [38]. All primers used for qRT-PCR were designed using the Primer3 software [73] and listed in Table S2 (Supplementary Material); the melting temperature was $60^{\circ} \mathrm{C}$, length of $20 \mathrm{nt}$, and amplicon length of $100 \mathrm{bp}$. Each qRT-PCR reaction $(20 \mu \mathrm{L})$ contained: $1.0 \mu \mathrm{L}$ of $25 \mathrm{ng} / \mu \mathrm{L}$ RNA, $1.0 \mu \mathrm{L}$ of $10 \mu \mathrm{M}$ of each forward and reverse primers, and $18 \mu \mathrm{L}$ of master mix QuantiNova SYBR Green RT-PCR Kit (Qiagen $囚$ ). qRT-PCR reactions were carried out in a StepOne PCR machine (Rotor-Gene Q 5plex HRM Platform) with the following reaction parameters: $10 \mathrm{~min}$ RT step at $50{ }^{\circ} \mathrm{C} ; 2 \mathrm{~min}$ PCR initial heat activation at $95{ }^{\circ} \mathrm{C}$, 40 two-step amplification cycles with $5 \mathrm{~s}$ denaturation at $95^{\circ} \mathrm{C}$ and $10 \mathrm{~s}$ annealing and extension at $60^{\circ} \mathrm{C}$; a final $15 \mathrm{~min}$ dissociation stage was used to generate a melting curve as well as well as verifying specificity of amplification products. Expression analysis and quantification were performed using the 
$2^{-\Delta \Delta C t}$ method (where $C_{T}$ is the cycling threshold); negative controls were carried out to confirm the absence of DNA contamination [74].

\subsection{GO Term Enrichment Analysis of Differentially Expressed Genes}

To identify overrepresented gene ontology (GO) terms in the set of differentially expressed genes, statistical GO enrichment analysis was performed using Ontologizer 2.0 [75]. GO annotations were taken from the annotated reference Uniprot proteome (UPID: UP000002357 accessed by Aug. 2018). Analysis was performed using the parent-child intersection method of Ontologizer followed by Benjamini-Hochberg multiple testing corrections. The "study set" corresponded to the frequency of GO terms in the differentially expressed gene set, while the "population set" indicated the whole set of proteins annotated with GO.

Supplementary Materials: The following are available online at http://www.mdpi.com/2079-6382/8/3/96/s1, Supplementary Material containing Table S1: Differential Gene Expression of Streptomyces clavuligerus, Table S2: Oligonucleotides used in this work.

Author Contributions: Conceptualization, L.P. and R.R.-E.; Formal analysis, L.P., J.F.A., and R.R.-E.; Funding acquisition, L.P., L.F.T. and R.R.-E.; Investigation, L.P., L.F.T.; Methodology, L.P., J.F.A., E.L. and R.R.-E.; Supervision, E.L., J.F.A., and R.R.-E.; Validation, L.P.; Writing—original draft, L.P.; Writing—review \& editing, L.P., L.F.T., E.L., J.F.A., and R.R.-E.

Funding: The authors kindly acknowledge the support of the Committee for Research Development (CODI) at the University of Antioquia (Grant No. PRG 2014-1065).

Acknowledgments: L. Pinilla and L. Toro thank Departamento Administrativo de Ciencias, Tecnología e Innovación COLCIENCIAS - Colombia for scholarships.

Conflicts of Interest: The authors declare that they have no conflict of interest.

\section{References}

1. Ser, H.L.; Law, J.W.F.; Chaiyakunapruk, N.; Jacob, S.A.; Palanisamy, U.D.; Chan, K.G.; Goh, B.H.; Lee, L.H. Fermentation conditions that affect clavulanic acid production in Streptomyces clavuligerus: A systematic review. Front. Microbiol. 2016, 7, 522. [CrossRef] [PubMed]

2. Liras, P.; Gomez-Escribano, J.P.; Santamarta, I. Regulatory mechanisms controlling antibiotic production in Streptomyces clavuligerus. J. Ind. Microbiol. Biotechnol. 2008, 35, 667-676. [CrossRef]

3. Saudagar, P.S.; Survase, S.A.; Singhal, R.S. Clavulanic acid: A review. Biotechnol. Adv. 2008, 26, 335-351. [CrossRef] [PubMed]

4. Reading, C.; Cole, M. Clavulanic acid: A beta-lactamase-inhiting beta-lactam from Streptomyces clavuligerus. Antimicrob. Agents Chemother. 1977, 11, 852-857. [CrossRef] [PubMed]

5. Wang, Y.-H.; Yang, B.; Ren, J.; Dong, M.-L.; Liang, D.; Xu, A.-L. Optimization of medium composition for the production of clavulanic acid by Streptomyces clavuligerus. Process. Biochem. 2005, 40, 1161-1166. [CrossRef]

6. Gouveia, E.R.; Baptista-Neto, A.; Badino, A.C.; Hokka, C.O. Optimisation of medium composition for clavulanic acid production by Streptomyces clavuligerus. Biotechnol. Lett. 2001, 23, 157-161. [CrossRef]

7. Higo, A.; Hara, H.; Horinouchi, S.; Ohnishi, Y. Genome-wide distribution of AdpA, a global regulator for secondary metabolism and morphological differentiation in streptomyces, revealed the extent and complexity of the AdpA regulatory network. DNA Res. 2012, 19, 259-273. [CrossRef]

8. Tahlan, K.; Anders, C.; Jensen, S.E. The paralogous pairs of genes involved in clavulanic acid and clavam metabolite biosynthesis are differently regulated in Streptomyces clavuligerus. J. Bacteriol. 2004, 186, 6286-6297. [CrossRef]

9. Paradkar, A. Clavulanic acid production by Streptomyces clavuligerus: Biogenesis, regulation and strain improvement. J. Antibiot. (Tokyo) 2013, 66, 411-420. [CrossRef]

10. Vivancos, A.P.; Guell, M.; Dohm, J.C.; Serrano, L.; Himmelbauer, H. Strand-specific deep sequencing of the transcriptome. Genome Res. 2010, 20, 989-999. [CrossRef]

11. Wang, Z.; Gerstein, M.; Snyder, M. RNA-Seq: A revolutionary tool for transcriptomics. Nat. Rev. Genet. 2009, 10, 57-63. [CrossRef] [PubMed] 
12. Ortiz, S.C.A.; Hokka, C.O.; Badino, A.C. Utilization of soybean derivatives on clavulanic acid production by Streptomyces clavuligerus. Enzyme Microb. Technol. 2007, 40, 1071-1077. [CrossRef]

13. Kirk, S.; Avignone-rossa, C.A.; Bushell, M.E. Growth limiting substrate affects antibiotic production and associated metabolic fluxes in Streptomyces clavuligerus. Biotechnol. Lett. 2000, 22, 1803-1809. [CrossRef]

14. Medema, M.H.; Alam, M.T.; Breitling, R.; Takano, E. The future of industrial antibiotic production: From random mutagenesis to synthetic biology. Bioeng. Bugs 2011, 2, 230-233. [CrossRef] [PubMed]

15. Ramirez-Malule, H.; Junne, S.; Nicolás Cruz-Bournazou, M.; Neubauer, P.; Ríos-Estepa, R. Streptomyces clavuligerus shows a strong association between TCA cycle intermediate accumulation and clavulanic acid biosynthesis. Appl. Microbiol. Biotechnol. 2018, 102, 4009-4023. [CrossRef] [PubMed]

16. Ramirez-Malule, H.; Restrepo, A.; Cardona, W.; Junne, S.; Neubauer, P.; Rios-Estepa, R. Inversion of the stereochemical configuration (3S, 5S)-clavaminic acid into (3R, 5R)-clavulanic acid: A computationally-assisted approach based on experimental evidence. J. Theor. Biol. 2016, 395, 40-50. [CrossRef]

17. Toro, L.; Pinilla, L.; Avignone-Rossa, C.; Ríos-Estepa, R. An enhanced genome-scale metabolic reconstruction of Streptomyces clavuligerus identifies novel strain improvement strategies. Bioprocess Biosyst. Eng. 2018, 41, 657-669. [CrossRef]

18. Ünsald1, E.; Kurt-Kızıldoğan, A.; Voigt, B.; Becher, D.; Özcengiz, G. Proteome-wide alterations in an industrial clavulanic acid producing strain of Streptomyces clavuligerus. Synth. Syst. Biotechnol. 2017, 2, 39-48. [CrossRef]

19. Rapaport, F.; Khanin, R.; Liang, Y.; Pirun, M.; Krek, A.; Zumbo, P.; Mason, C.E.; Socci, N.D.; Betel, D. Comprehensive evaluation of differential gene expression analysis methods for RNA-seq data. Genome Biol. 2013, 14, R95. [CrossRef]

20. Gouveia, E.R.; Baptista-Neto, A.; Azevedo, A.G.; Badino, A.C.; Hokka, C.O. Improvement of clavulanic acid production by Streptomyces clavuligerus in medium containing soybean derivatives. World J. Microbiol. Biotechnol. 1999, 15, 623-627. [CrossRef]

21. Pinilla, L.; Toro, L.F.; Avignone-Rossa, C.; Peñuela, M.; Rios-Estepa, R. Streptomyces clavuligerus strain selection for clavulanic acid biosynthesis: A study based on culture composition effects and statistical analysis. DYNA 2018, 85, 111-118. [CrossRef]

22. Rioseras, B.; López-García, M.T.; Yagüe, P.; Sánchez, J.; Manteca, Á. Mycelium differentiation and development of Streptomyces coelicolor in lab-scale bioreactors: Programmed cell death, differentiation, and lysis are closely linked to undecylprodigiosin and actinorhodin production. Bioresour. Technol. 2014, 151, 191-198. [CrossRef]

23. Denser Pamboukian, C.R.; Guimarães, L.M.; Facciotti, M.C.R. Applications of image analysis in the characterization of Streptomyces olindensis in submerged culture. Braz. J. Microbiol. 2002, 33, 17-21. [CrossRef]

24. Martínez-Burgo, Y.; Álvarez-Álvarez, R.; Rodríguez-García, A.; Liras, P. The Pathway-Specific Regulator ClaR of Streptomyces clavuligerus Has a Global Effect on the Expression of Genes for Secondary Metabolism and Differentiation. Appl. Environ. Microbiol. 2015, 81, 6637-6648. [CrossRef]

25. Bignell, D.R.D.; Tahlan, K.; Colvin, K.R.; Jensen, S.E.; Leskiw, B.K. Expression of ccaR, encoding the positive activator of cephamycin $\mathrm{C}$ and clavulanic acid production in Streptomyces clavuligerus, is dependent on bldG. Antimicrob. Agents Chemother. 2005, 49, 1529-1541. [CrossRef]

26. Álvarez-Álvarez, R.; Rodríguez-García, A.; Martínez-Burgo, Y.; Martín, J.F.; Liras, P. Transcriptional studies on a Streptomyces clavuligerus oppA2 deletion mutant: $\mathrm{N}$-acetylglycyl-clavaminic acid is an intermediate of clavulanic acid biosynthesis. Appl. Environ. Microbiol. 2018, 84, e01701-e01718. [CrossRef]

27. Tahlan, K.; Park, H.U.; Wong, A.; Beatty, P.H.; Jensen, S.E. Two sets of paralogous genes encode the enzymes involved in the early stages of clavulanic acid and clavam metabolite biosynthesis in Streptomyces clavuligerus. Antimicrob. Agents Chemother. 2004, 48, 930-939. [CrossRef]

28. Rodríguez-García, A.; de la Fuente, A.; Pérez-Redondo, R.; Martín, J.F.; Liras, P. Characterization and expression of the arginine biosynthesis gene cluster of Streptomyces clavuligerus. J. Mol. Microbiol. Biotechnol. 2000, 2, 543-550.

29. Kuo-Cheng, C.; Yun-Huin, L.; Jane-Yii, W.; Sz-Chwun, J.H. Enhancement of clavulanic acid production in Streptomyces clavuligerus with ornithine feeding. Enzyme Microb. Technol. 2003, 32, 152-156. 
30. Marsh, A.J.; O'Sullivan, O.; Ross, R.P.; Cotter, P.D.; Hill, C. In silico analysis highlights the frequency and diversity of type 1 lantibiotic gene clusters in genome sequenced bacteria. BMC Genom. 2010, 11, 679. [CrossRef]

31. Imran, S.; Shaaban, K.A.; Hasnain, S. Identification, isolation and optimization of antifungal metabolites from the Streptomyces malachitofuscus CTF9. Braz. J. Microbiol. 2011, 42, 592-604.

32. Freiberg, J.A.; Le Breton, Y.; Tran, B.Q.; Scott, A.J.; Harro, J.M.; Ernst, R.K.; Goo, Y.A.; Mongodin, E.F.; Goodlett, D.R.; McIver, K.S.; et al. Global analysis and comparison of the transcriptomes and proteomes of group A Streptococcus biofilms. mSystems 2016, 1, e00149-16. [CrossRef]

33. Yagüe, P.; Rodríguez-García, A.; López-García, M.T.; Martín, J.F.; Rioseras, B.; Sánchez, J.; Manteca, A. Transcriptomic analysis of Streptomyces coelicolor differentiation in solid sporulating cultures: First compartmentalized and second multinucleated mycelia have different and distinctive transcriptomes. PLOS ONE 2013, 8, e60665. [CrossRef]

34. Hesketh, A.; Bucca, G.; Laing, E.; Flett, F.; Hotchkiss, G.; Smith, C.P.; Chater, K.F. New pleiotropic effects of eliminating a rare tRNA from Streptomyces coelicolor, revealed by combined proteomic and transcriptomic analysis of liquid cultures. BMC Genom. 2007, 8, 261. [CrossRef]

35. Castro-Melchor, M.; Charaniya, S.; Karypis, G.; Takano, E.; Hu, W.S. Genome-wide inference of regulatory networks in Streptomyces coelicolor. BMC Genom. 2010, 11, 578. [CrossRef]

36. Alvarez-Álvarez, R.; Rodríguez-García, A.; Santamarta, I.; Pérez-Redondo, R.; Prieto-Domínguez, A.; Martínez-Burgo, Y.; Liras, P. Transcriptomic analysis of Streptomyces clavuligerus $\Delta$ ccaR:tsr: Effects of the cephamycin C-clavulanic acid cluster regulator CcaR on global regulation. Microb. Biotechnol. 2014, 7, 221-231. [CrossRef]

37. Kato, J.; Suzuki, A.; Yamazaki, H.; Ohnishi, Y.; Horinouchi, S. Control by A-factor of a metalloendopeptidase gene involved in aerial mycelium formation in Streptomyces griseus. J. Bacteriol. 2002, 184, 6016-6025. [CrossRef]

38. Robles-Reglero, V.; Santamarta, I.; Álvarez-Álvarez, R.; Martín, J.F.; Liras, P. Transcriptional analysis and proteomics of the holomycin gene cluster in overproducer mutants of Streptomyces clavuligerus. J. Biotechnol. 2013, 163, 69-76. [CrossRef]

39. Medema, M.H.; Alam, M.T.; Heijne, W.H.M.; van den Berg, M.A.; Müller, U.; Trefzer, A.; Bovenberg, R.A.L.; Breitling, R.; Takano, E. Genome-wide gene expression changes in an industrial clavulanic acid overproduction strain of Streptomyces clavuligerus. Microb. Biotechnol. 2011, 4, 300-305. [CrossRef]

40. Maranesi, G.L.; Baptista-Neto, A.; Hokka, C.O.; Badino, A.C. Utilization of vegetable oil in the production of clavulanic acid by Streptomyces clavuligerus ATCC 27064. World J. Microbiol. Biotechnol. 2005, 21, 509-514. [CrossRef]

41. Hodgson, D.A. Primary metabolism and its control in streptomycetes: A most unusual group of bacteria. Adv. Microb. Physiol. 2000, 42, 47-238.

42. Ives, P.R.; Bushell, M.E. Manipulation of the physiology of clavulanic acid production in Streptomyces clavuligerus. Microbiology 1997, 143, 3573-3579. [CrossRef]

43. Belmar-Beiny, M.T.; Thomas, C.R. Morphology and clavulanic acid production of Streptomyces clavuligerus: Effect of stirrer speed in batch fermentations. Biotechnol. Bioeng. 1991, 37, 456-462. [CrossRef]

44. Kim, Y.-M.; Kim, J. Formation and dispersion of mycelial pellets of Streptomyces coelicolor A3(2). J. Microbiol. 2004, 42, 64-67.

45. Kyung, Y.S.; Hu, W.S.; Sherman, D.H. Analysis of temporal and spatial expression of the CcaR regulatory element in the cephamycin C biosynthetic pathway using green fluorescent protein. Mol. Microbiol. 2001, 40, 530-541. [CrossRef]

46. Medema, M.H.; Trefzer, A.; Kovalchuk, A.; Van Den Berg, M.; Müller, U.; Heijne, W.; Wu, L.; Alam, M.T.; Ronning, C.M.; Nierman, W.C.; et al. The sequence of a 1.8-Mb bacterial linear plasmid reveals a rich evolutionary reservoir of secondary metabolic pathways. Genome Biol. Evol. 2010, 2, 212-224. [CrossRef]

47. Zhou, Z.; Gu, J.; Du, Y.-L.; Li, Y.-Q.; Wang, Y. The -omics era- toward a systems-level understanding of Streptomyces. Curr. Genom. 2011, 12, 404-416. [CrossRef]

48. Borukhov, S.; Severinov, K. Role of the RNA polymerase sigma subunit in transcription initiation. Res. Microbiol. 2002, 153, 557-562. [CrossRef]

49. Jnawali, H.N.; Liou, K.; Sohng, J.K. Role of $\sigma$-factor (orf21) in clavulanic acid production in Streptomyces clavuligerus NRRL3585. Microbiol. Res. 2011, 166, 369-379. [CrossRef] 
50. Santos, C.L.; Correia-Neves, M.; Moradas-Ferreira, P.; Mendes, M.V. A walk into the LuxR regulators of Actinobacteria: Phylogenomic distribution and functional diversity. PLoS ONE 2012, 7, e46758. [CrossRef]

51. Jensen, S.E. Biosynthesis of clavam metabolites. J. Ind. Microbiol. Biotechnol. 2012, 39, 1407-1419. [CrossRef]

52. Ozcengiz, G.; Demain, A.L. Recent advances in the biosynthesis of penicillins, cephalosporins and clavams and its regulation. Biotechnol. Adv. 2013, 31, 287-311. [CrossRef]

53. López-García, M.T.; Santamarta, I.; Liras, P. Morphological differentiation and clavulanic acid formation are affected in a Streptomyces clavuligerus adpA-deleted mutant. Microbiology 2010, 156, 2354-2365. [CrossRef]

54. Akanuma, G.; Hara, H.; Ohnishi, Y.; Horinouchi, S. Dynamic changes in the extracellular proteome caused by absence of a pleiotropic regulator AdpA in Streptomyces griseus. Mol. Microbiol. 2009, 73, 898-912. [CrossRef]

55. Banbula, A.; Potempa, J.; Travis, J.; Fernandez-Catalán, C.; Mann, K.; Huber, R.; Bode, W.; Medrano, F. Amino-acid sequence and three-dimensional structure of the Staphylococcus aureus metalloproteinase at 1.72 A resolution. Structure 1998, 6, 1185-1193. [CrossRef]

56. Meeske, A.J.; Rodrigues, C.D.A.; Brady, J.; Lim, H.C.; Bernhardt, T.G.; Rudner, D.Z. High-Throughput Genetic Screens Identify a Large and Diverse Collection of New Sporulation Genes in Bacillus subtilis. PLoS Biol. 2016, 14, e1002341. [CrossRef]

57. Kim, D.W.; Kang, S.G.; Kim, I.S.; Lee, B.K.; Rho, Y.T.; Lee, K.J. Proteases and protease inhibitors produced in streptomycetes and their roles in morphological differentiation. J. Microbiol. Biotechnol. 2006, 16, 5-14.

58. BLAST Nucleotide BLAST: Search Nucleotide Databases Using a Nucleotide Query. Available online: https://blast.ncbi.nlm.nih.gov/Blast.cgi (accessed on 12 June 2019).

59. Ramos, J.L.; Martinez-Bueno, M.; Molina-Henares, A.J.; Teran, W.; Watanabe, K.; Zhang, X.; Gallegos, M.T.; Brennan, R.; Tobes, R. The TetR family of transcriptional repressors. Microbiol. Mol. Biol. Rev. 2005, 69, 326-356. [CrossRef]

60. Ferguson, N.L.; Peña-Castillo, L.; Moore, M.A.; Bignell, D.R.D.; Tahlan, K. Proteomics analysis of global regulatory cascades involved in clavulanic acid production and morphological development in Streptomyces clavuligerus. J. Ind. Microbiol. Biotechnol. 2016, 43, 537-555. [CrossRef]

61. Shepherd, M.D.; Kharel, M.K.; Bosserman, M.A.; Rohr, J. Laboratory maintenance of Streptomyces species. Curr. Protoc. Microbiol. 2010, 18, 10E.1.1-10E.1.8.

62. Romero, J.; Liras, P.; Martín, J.F. Dissociation of cephamycin and clavulanic acid biosynthesis in Streptomyces clavuligerus. Appl. Microbiol. Biotechnol. 1984, 20, 318-325. [CrossRef]

63. Gómez-Ríos, D.; Ramírez-Malule, H.; Neubauer, P.; Junne, S.; Ríos-Estepa, R. Degradation kinetics of clavulanic acid in fermentation broths at low temperatures. Antibiotics 2019, 8, 6. [CrossRef]

64. Nakamura, G.R. Microdetermination of Phosphorus. Anal. Chem. 1952, 24, 1372. [CrossRef]

65. Bok, S.H.; Demain, A.L. An improved colorimetric assay for polyols. Anal. Biochem. 1977, 81, 18-20. [CrossRef]

66. Pederson, T. Use of diphenylamine as a colorimetric reagent for ribonucleic acid. Anal. Biochem. 1969, 28, 35-46. [CrossRef]

67. Trapnell, C.; Hendrickson, D.G.; Sauvageau, M.; Goff, L.; Rinn, J.L.; Pachter, L. Differential analysis of gene regulation at transcript resolution with RNA-seq. Nat. Biotechnol. 2013, 31, 46-53. [CrossRef]

68. Andrews, S. FastQC: A Quality Control Tool for High Throughput Sequence Data. Available online: https://www.bioinformatics.babraham.ac.uk/projects/fastqc (accessed on 8 May 2018).

69. HannonLab FASTX toolkit. Available online: http://hannonlab.cshl.edu/fastx_toolkit/ (accessed on 4 January 2017).

70. Langmead, B.; Salzberg, S.L. Fast gapped-read alignment with Bowtie 2. Nat. Methods 2012, 9, 357-359. [CrossRef]

71. Anders, S.; Pyl, P.T.; Huber, W. HTSeq-A Python framework to work with high-throughput sequencing data. Bioinformatics 2015, 31, 166-169. [CrossRef]

72. Robinson, M.D.; McCarthy, D.J.; Smyth, G.K. edgeR: A Bioconductor package for differential expression analysis of digital gene expression data. Bioinformatics 2010, 26, 139-140. [CrossRef]

73. Untergasser, A.; Cutcutache, I.; Koressaar, T.; Ye, J.; Faircloth, B.C.; Remm, M.; Rozen, S.G. Primer3-New capabilities and interfaces. Nucleic Acids Res. 2012, 40, e115. [CrossRef] 
74. Livak, K.J.; Schmittgen, T.D. Analysis of relative gene expression data using real-time quantitative PCR and the 2- $\Delta \Delta C$ T method. Methods 2001, 25, 402-408. [CrossRef]

75. Bauer, S.; Grossmann, S.; Vingron, M.; Robinson, P.N. Ontologizer 2.0-A multifunctional tool for GO term enrichment analysis and data exploration. Bioinformatics 2008, 24, 1650-1651. [CrossRef]

(C) 2019 by the authors. Licensee MDPI, Basel, Switzerland. This article is an open access article distributed under the terms and conditions of the Creative Commons Attribution (CC BY) license (http://creativecommons.org/licenses/by/4.0/). 